gave them a short talk, mentioning James Lind, then presented the results of my trial and argued that there was a major "epidemic" due to a diet deficient in vitamin B. I said that it was possibly wet beri-beri. I asked for a lot of yeast and more food. They said, as usual, that they would see what they could do.

I thought that I had played my last card and lost, but the unexpected happened, the Germans produced a lot of yeast. We

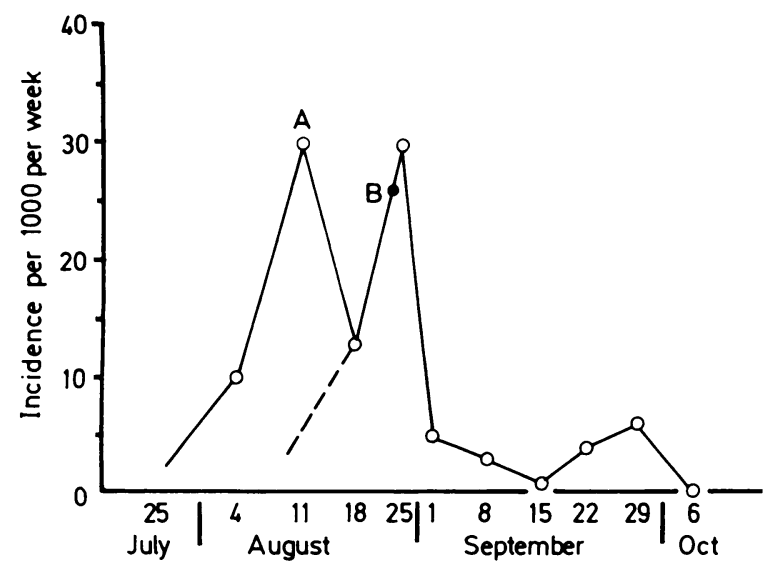

A Level of diagnosis is changed from oedema above ankle to oedema above knee

B Clinical trial

FIG 2-Probable increase and decrease of oedema. gave two teaspoonfuls a day to those with oedema above the knee, and one teaspoonful to those with ankle oedema. Figure 1 , which is copied from my original notes, shows the incidence. It is difficult to follow because of the change in the level of diagnosis from "ankle" oedema to oedema "above the knee" at point A. Figure 2 gives the probable rise and fall. As the oedema slowly disappeared (and the shooting stopped) morale in the camp improved. The fear of a major catastrophe passed and we began to relax. The camp was slowly evacuated, but a few survivors including myself remained until December 1941.

\section{A little bit of science, plus luck}

On reflection, it was not a good trial. I was testing the wrong hypothesis. The oedema was not wet beri-beri. Furthermore, the numbers were too small, the time too short, and the outcome measurements poor. Yet the treatment worked. I still do not know why. I imagine that the simplest explanation is that the small amount of protein in the yeast raised the plasma proteins sufficiently to correct fluid balance.

There are two additional points worth making. Firstly, it could be argued that the trial was randomised and controlled, although this last was somewhat inadequate. In those early days, when the randomised controlled trial was little known in medicine, this was something of an achievement. At the same time I can take little credit as the design of the trial was largely fortuitous. Secondly, the German doctor's remark, when I asked for more help, was "Ärtze sind überflüssing" ("doctors are superfluous"). This was probably correct, but it was amazing what a little bit of science and a little bit of luck achieved.

\title{
An unusual source of hospital wound infection
}

\author{
W A DICKSON, PAMELA BOOTHMAN, KAY HARE
}

The use of leeches in medical treatment is probably now regarded as of only historical interest, but they are, in fact, still widely used in plastic surgery to decongest flaps. ${ }^{12}$ Hirudo medicinalis-the medicinal leech-harbours bacteria, and Whitlock et al pointed out that it might be a source of infection. ${ }^{3}$ We present what we believe to be the first report of infection traced to this source.

\section{Case report}

A 27 year old white woman, para 3, who had had a left simple mastectomy for a stage I carcinoma of the breast two years previously was referred for reconstruction. On admission she was slim with an oblique mastectomy scar but no evidence of local, nodal, or metastatic disease. She had a moderate amount of redundant abdominal skin. There were no abdominal scars. A contralateral rectus abdominis flap was raised to reconstruct the left breast without using a prosthesis. ${ }^{4}$ Immediately after operation the flap was congested, but this improved spontaneously over the next few hours. On the first postoperative day, however, the flap became progressively more congested and a decision was made to apply leeches to it. They were attached regularly for four days and appeared to be effective

Plastic Surgery Unit, Canniesburn Hospital, Glasgow

W A DICKSON, FRCS, senior house officer in plastic surgery (present appointment: registrar in plastic surgery, St Luke's Hospital, Bradford)

Department of Bacteriology, Glasgow Royal Infirmary, Glasgow G4 OSF PAMELA BOOTHMAN, FIMLS, senior medical laboratory scientific officer KAY HARE, MD, DCP, consultant bacteriologist in reducing the congestion, except in an area on the superior aspect, which subsequently became necrotic (figure).

On the fifth postoperative day erythema of the flap and surrounding skin became apparent, and a course of cephradine was started. The erythema improved, and she was discharged on the ninth day. Three days later she returned with a haematoma, which was aspirated. Although there was no cellulitis at this time, within 24 hours she developed fever with signs of inflammation of the breast and a discharge of pus from the superior suture

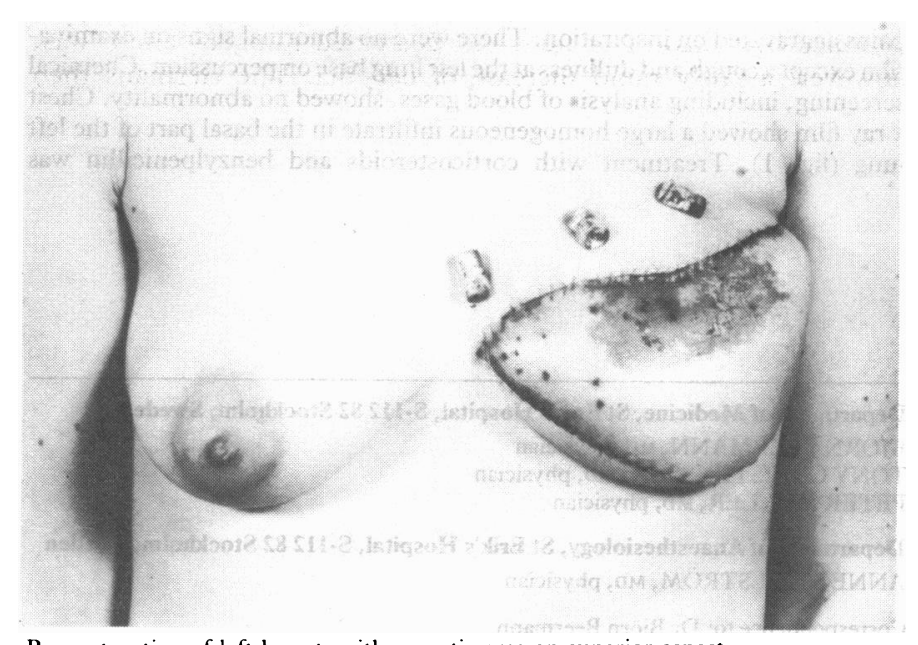


line. She was readmitted for drainage, and when the infection had subsided the flap was debrided and resutured. The abdominal wound healed well without infection.

Bacteriological findings-Direct examination of the haematoma fluid showed numerous polymorphs with intracellular and extracellular Gram negative bacilli $(2 \times 0.5 \mu \mathrm{m})$. The fluid and a swab from the wound yielded a pure growth of a non-lactose fermenting, oxidase positive, aerobic Gram negative bacillus, which was identified by the API system (appareil procédés d'identification) as Aeromonas hydrophila. As this organism is known to be harboured by leeches, ${ }^{5}$ two from the batch used to treat the patient were examined bacteriologically. After they had crawled over plates of blood agar and CLED agar they were killed, cut up, and inoculated on to various media, which were then incubated aerobically and anaerobically. The water in which the leeches had been transported was similarly cultured. A hydrophila was isolated from the three sets of cultures; in addition a strain of Providencia spp was isolated from the transport water. The isolates of $A$ hydrophila had the same pattern of antimicrobial sensitivity as that reported by Millership et $a l^{6}$ - that is, they were sensitive to sulphonamide, tetracycline, chloramphenicol, gentamicin, tobramycin, and both cefuroxime and cefotaxime. They were resistant to ampicillin, trimethoprim, erythromycin, and cephradine.

\section{Comment}

Leeches commonly harbour $A$ hydrophila. Whitlock et al drew attention to the possible risk of infection with this organism as a result of using leeches in microsurgery but did not themselves report any such infections. ${ }^{3}$ The wound infection described here was almost certainly acquired from the leeches used to decongest the flap in the reconstruction of the patient's breast. Although not common, infection due to $A$ hydrophila has been reported to have been acquired from various sources including fresh water, ${ }^{7}$ and clearly it cannot be disregarded as a human pathogen. Our report confirms that the leech is a potential source of wound infection.

We thank Mr M H C Webster for allowing us to report this case and Professor Morag C Timbury for helpful advice.

\section{References}

I Derganc $\mathrm{M}, \mathrm{Zdravid} \mathrm{F}$. Venous congestion of flaps treated by application of leeches. Br Y Plast. Surg 1960;13:187-92

2 Henderson HP, Matti B, Laing AG, Morelli S, Sully I. Avulsion of the scalp treated by microvascular repair. The use of leeches for post-operative congestion. $\mathrm{Br} \mathcal{J}$ Plast Surg

3 Whitlock MR, O'Hare PM, Sanders R, Morrow NC. The medicinal leech and its use in plastic surgery: a possible cause of infection. Br 7 Plost Surg 1983:36:240-4

Hartramp CR, Schefan M Black PW Breast reconstruction with transverse abdominal island flap. Plast Reconstr. Surg 1982;69:216-24.

5 Jennings JB, Van der Lande VM. Histochemical and bacteriological studies on digestion in nine species of leeches (annelida: hirudinea). Biol Bull 1967;33:166-71.

Millership SE, Curnow SR, Chattopadhyay B. Faecal carriage rate of Aeromonas hydrophila J Clin Pathol 1983;36:920-3.

McCracken AW, Barkley R. Isolation of aeromonas species from clinical sources. $\mathcal{f}$ Clin Pathol 1972;25:970-5

\title{
Lipoid pneumonia: an occupational hazard of fire eaters
}

\author{
BJÖRN BEERMANN， TONY CHRISTENSSON， PETER MÖLLER， ANNE STILLSTRÖM
}

Liquid paraffins are used as purgatives or nasal drops, and for lighting charcoal for barbecues: a low oral toxicity and a high flame point make them suitable for both purposes. Aspiration of paraffins into the lungs, however, may have deleterious effects. ${ }^{1-3} \mathrm{We}$ report a severe case of pneumonia caused by inhalation of liquid paraffins in a fire eating woman.

\section{Case report}

A 29 year old female clown was admitted after inhaling a mouthful of an ignition fluid containing $20 \%$ isoparaffins and $80 \% \mathrm{n}$-paraffins. The accident had occurred while she was training to be a fire eater. The normal procedure is to blow out the fluid against a burning stick. Because of the high flame point only fluid in the form of an aerosol around the stick will burn, and there is small risk of the fire spreading to the mouth.

The patient suffered from cough, dyspnoea, and left sided severe chest pains aggravated on inspiration. There were no abnormal signs on examination except a cough and dullness at the left lung base on percussion. Chemical screening, including analysis of blood gases, showed no abnormality. Chest $x$ ray film showed a large homogeneous infiltrate in the basal part of the left lung (fig. 1). Treatment with corticosteroids and benzylpenicillin was

Department of Medicine, St Erik's Hospital, S-112 82 Stockholm, Sweden BJÖRN BEERMANN, MD, physician TONY CHRISTENSSON, MD, physician PETER MÖLLER, MD, physician

Department of Anaesthesiology, St Erik's Hospital, S-112 82 Stockholm, Sweden ANNE STILLSTRÖM, MD, physician

Correspondence to: Dr Björn Beermann. started. The chest pain was very intense and was relieved first after intercostal blockade and high doses of dextropropoxyphene and paracetamol.

The patient's condition deteriorated during the next week with fever up to $39 \cdot 4^{\circ} \mathrm{C}$. Analysis of blood gases showed a fall of oxygen pressure $\mathrm{PO}_{2}$ to $8 \cdot 4$ $\mathrm{kPa}(63 \mathrm{~mm} \mathrm{Hg})$, and the pulmonary infiltrates increased in size and pleural effusion appeared (fig 2). Erythrocyte sedimentation rate increased to 131

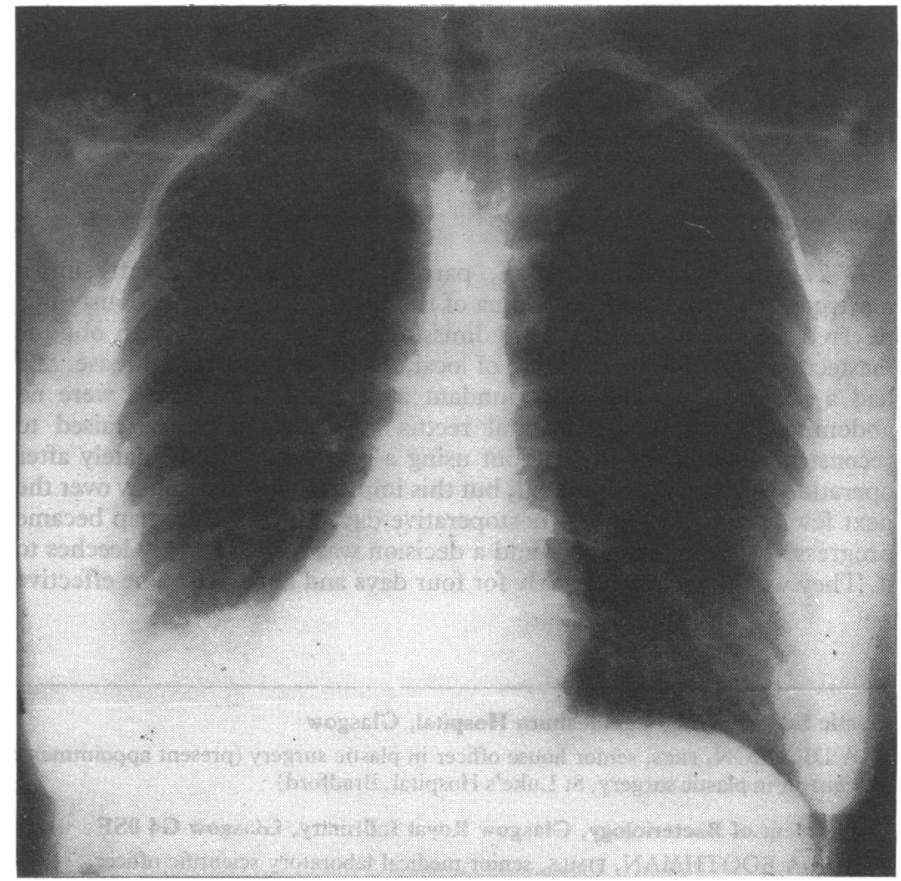

FIG 1 -Chest $x$ ray film immediately after inhalation of liquid paraffins. 